\title{
Assessing the distribution of a Vulnerable felid species: threats from human land use and climate change to the kodkod Leopardus guigna
}

\author{
Griet A.E. Cuyckens, Miriam M. Morales and Marcelo F. Tognelli
}

\begin{abstract}
Climate change and habitat fragmentation are considered key pressures on biodiversity, and mammalian carnivores with a limited geographical distribution are particularly vulnerable. The kodkod Leopardus guigna, a small felid endemic to the temperate forests of southern Chile and Argentina, has the smallest geographical range of any New World felid. Although the species occurs in protected areas in both countries, it is not known how well these areas protect the kodkod either currently or under climate change scenarios. We used species distribution models and spatial analyses to assess the distribution of the kodkod, examining the effects of changes in human land use and future climate change. We also assessed the species' present representation in protected areas and in light of climate change scenarios. We found that the kodkod has already lost $5.5 \%$ of its range as a result of human land use, particularly in central areas of its distribution with intermediate habitat suitability. Climate change, together with human land use, will affect $40 \%$ of the kodkod's present potential distribution by the year 2050. Currently, $12.5 \%$ of the species' potential distribution lies in protected areas and this will increase to $14 \%$ in the future. This increase does not, however, mean an increase in protected habitat but rather a reduction of the species' total potential range; a relatively larger percentage will be protected in Argentina than in Chile but the species is more susceptible to extinction in Argentina and the Chilean Matorral.
\end{abstract}

Keywords Argentina, kodkod, Leopardus guigna, MaxEnt, protected areas, species distribution modelling, temperate forests

This paper contains supplementary material that can be found online at http://journals.cambridge.org

\footnotetext{
GRIET A.E. CuYCKENS (Corresponding author) and Miriam M. Morales Consejo Nacional de Investigaciones Científicas y Técnicas, Centro de Estudios Territoriales Ambientales y Sociales, Facultad de Ciencias Agrarias, Universidad Nacional de Jujuy, Alberdi 47, 4600 San Salvador de Jujuy, Argentina. E-mail grietcuyckens@yahoo.com

Marcelo F. Tognelli IUCN-Consevation International Biodiversity Assessment Unit, Conservation International, Arlington, Virginia, USA, and Instituto Argentino de Investigaciones de Zonas Áridas, Consejo Nacional de Investigaciones Científicas y Técnicas, Mendoza, Argentina

Received 21 March 2013. Revision requested 7 June 2013.

Accepted 9 September 2013. First published online 7 October 2014.
}

\section{Introduction}

Climate change and destruction of natural habitats $\checkmark$ through human activities are major threats to terrestrial biodiversity. These pressures have led to substantial range contractions and species' extinctions (Parmesan \& Yohe, 2003; Root et al., 2003; Opdam \& Wascher, 2004), including for mammals (Schipper et al., 2008), and species at high altitudes are particularly vulnerable (Innes, 1991; Diaz \& Bradley, 1997; Burns et al., 2003; Thomas et al., 2004). Knowledge of the geographical distribution of species is essential to assess these threats (Regan et al., 2000; Conrad et al., 2006) but data on the distribution of rare species is limited (Hernandez et al., 2006; Thorn et al., 2009).

One of the most effective ways to protect species and their habitats is through the establishment of protected areas. Historically, protected areas were established opportunistically, assigning places with low potential for economic development and high potential for tourism (Margules \& Pressey, 2000; Rodrigues et al., 2004; Burkart et al., 2007; Marinaro et al., 2012). To assess the value of protected areas for protecting a particular species, a GAP analysis (Jennings, 2000) can be performed by overlaying a distribution map of biological attributes onto a map of protected areas.

The kodkod Leopardus guigna is a rare, small felid native to Chilean and Argentinian temperate forests, with the smallest geographical range of the New World felids (Oliveira, 1994; Nowell \& Jackson, 1996; Sunquist \& Sunquist, 2002, 2009; Acosta \& Lucherini, 2008). The species is categorized as Vulnerable on the IUCN Red List (Acosta \& Lucherini, 2008) and in Argentina (Díaz \& Ojeda, 2000); in Chile, it is classified as Inadequately Known and Rare (CONAMA, 2007). Two subspecies are recognized (Cabrera, 1957; Wilson \& Reeder, 2005; Napolitano et al., 2013); L. guigna tigrillo (=L. guigna molinae), which inhabits the Chilean Matorral and sclerophyll woodlands and forests in northern and central Chile (between the Coquimbo and BíoBío Regions), and L. guigna guigna, which inhabits Valdivian temperate rainforest and north Patagonian forest (from the Araucanía to Aysén Regions, including Chiloé Island), and the Andean Patagonian forest (western Neuquén, Río Negro and Chubut Provinces in south-western Argentina; Osgood, 1943; Nowell \& Jackson, 1996; Freer, 2004). The restricted distribution of the kodkod and its habitat specificity make it particularly vulnerable to changes in land use and climate (Araújo et al., 2008). 

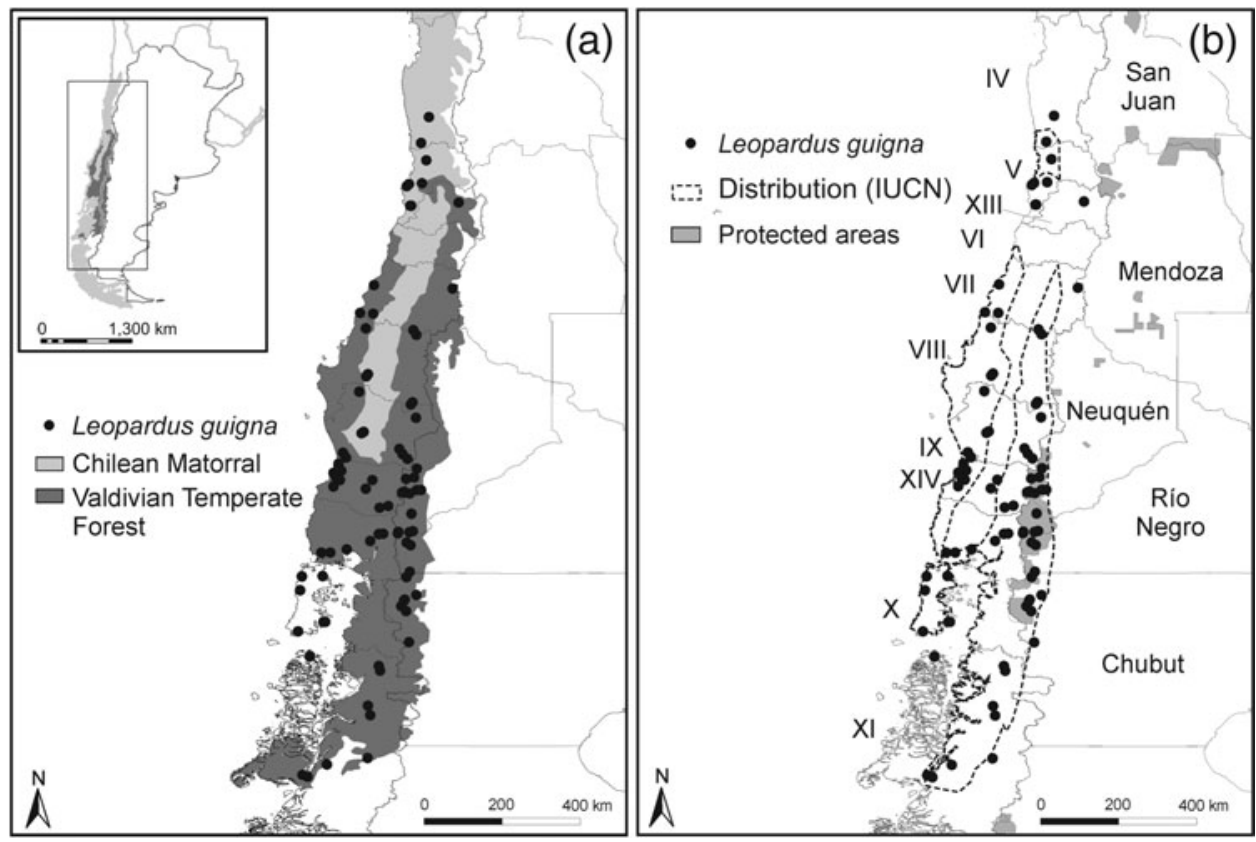

Fig. 1 Presence records of the kodkod Leopardus guigna in Chile and Argentina overlain on (a) the Chilean Matorral and Valdivian Temperate Forest, and (b) protected areas and the species' distribution as recorded on the IUCN Red List (Acosta \& Lucherini, 2008), with states. The rectangle on the inset indicates the location of the main map in South America.
Part of the kodkod's distribution includes Andean mountain ranges. Species inhabiting mountain ranges may shift their distributions to higher elevations or latitudes as a result of climate change (Hughes, 2000) but it is not clear if and how much the kodkod could migrate to higher altitudes because permanent snow naturally limits its distribution (Dunstone et al., 2002). There are several protected areas within the kodkod's range on the border between Argentina and Chile, and these areas are unlikely to be transformed to other uses as it is difficult to grow crops in this region (FAO, 2001). However, parts of these protected areas are currently covered with permanent snow and thus are not suitable habitat for the kodkod (Gálvez et al., 2013). The aims of this study were to update knowledge of the distribution of L. guigna based on the largest data set of historical and current records hitherto collected, to assess the effects of current human land use on the species' distribution, and to predict the species' future distribution, taking into consideration the effects of climate change. We also assess the kodkod's present representation in protected areas in light of climate change.

\section{Study area}

The Valdivian Temperate Forest of southern Chile and adjacent Argentina spans $35-48^{\circ} \mathrm{S}$ (Fig. 1a; Olson et al., 2001; WWF, 2006). It is recognized as an ecoregion with a high conservation priority by the Global 2000 initiative (Olson et al., 2001). Minimum and maximum mean annual temperatures are $7-21$ and $4-13{ }^{\circ} \mathrm{C}$ in the north and south of this ecoregion, respectively (CONAMA, 2007). Total annual precipitation varies between $1,000 \mathrm{~mm}$ in the north and $>6,000 \mathrm{~mm}$ in the south (Huber, 1979). The Chilean
Matorral ecoregion is a $100 \mathrm{~km}$-wide strip extending along the central part of the Chilean coast. It is characterized by a temperate Mediterranean climate, with rainy winters and dry summers. About $95 \%$ of the plant species of this region are endemic to Chile (WWF, 2006).

\section{Methods}

\section{Sources of biological data}

To avoid bias in geographical representation we included data representing the entire range of the kodkod (SánchezFernández et al., 2011). We included material from the following collections: American Museum of Natural History (AMNH, New York, USA), Field Museum of Natural History (FMNH, Chicago, USA), Colección del Grupo de Ecología Comportamental de Mamíferos (CGECM, Bahía Blanca, Argentina), and Museo Argentino de Ciencias Naturales 'Bernardino Rivadavia' (MACN, Buenos Aires, Argentina). We also compiled distribution records from the literature (Osgood, 1943; Nowell \& Jackson, 1996; Walker et al., 2003; Acosta-Jamett \& Simonetti, 2004; Freer, 2004; Tapia Friz, 2005; Coldwell, 2008; Gálvez et al., 2013), unpublished field records from the Sistema de Informacion Biodiversidad of the Administration of National Parks (Argentina), records provided by colleagues (the project Conservation and ecology of the huiña cat Leopardus guigna in the north-east of Patagonia, Argentina, courtesy M. Monteverde), and localities shared by the Cat Specialist Group (courtesy G. Acosta-Jamett). We compiled a total of 104 presence records spanning a period of 79 years. After cleaning the data (i.e. excluding records lacking environmental variables or records that could not be 
TABLE 1 Percentage contribution of the five (of a total of 22) variables that have the greatest contribution to the model of the present potential distribution of the kodkod Leopardus guigna (Present) and to models using three climate change scenarios (GFDL-CM2, CCMA$\mathrm{CGCM}_{3.1}$-T63, CSIRO-MK3.0; Ramirez \& Jarvis, 2008). See text for further details.

\begin{tabular}{lcccc}
\hline & Present & GFDL-CM2 & CCMA-CGCM3.1-T63 & CSIRO_MK3.0 \\
\hline Precipitation of coldest quarter & 68.9 & 70.3 & 68.4 & 68.9 \\
Precipitation seasonality & 0.8 & 11 & 9.9 & 11.7 \\
Mean temperature of coldest quarter & 10.8 & 2.9 & 2.8 & 3.2 \\
Mean temperature of driest quarter & 17.5 & 13.6 & 15.6 & 14 \\
Min. temperature of coldest quarter & 2.0 & 2.1 & 3.3 & 2.2 \\
\hline
\end{tabular}

georeferenced) and filtering records from the same pixel (i.e. c. $0.77 \mathrm{~km}^{2}$ ), we had 86 georeferenced independent localities for 1923-2002 (Fig. 1; Supplementary Table S1).We assigned coordinates using Google Earth 5.0.1 (Google Permissions, 2013) and gazetteers from DIVA-GIS (2013) and the Instituto Geográfico Nacional (Argentina). All records were transformed to decimal degrees using the geodetic datum WGS 84 .

\section{Environmental variables}

We used environmental variables from WorldClim (Hijmans et al., 2005), commonly used in ecological niche modelling (Loiselle et al., 2010), and altitude derived from a digital elevation model produced by NASA (Shuttle Radar Topographic Mission), from which we derived slope. These variables performed well in modelling potential distribution of the flat headed cat Prionailurus planiceps (Wilting et al., 2010), Andean cat Leopardus jacobita (Marino et al., 2011) and jaguar Panthera onca (Tôrres et al., 2008).

To generate predictive distribution models we used projections of the same climatic variables for the year 2050. There is a lack of agreement as to which climate models are most appropriate for predicting species distributions (Pierce et al., 2009). We therefore used a selection of three scenarios for 2050, derived from IPCC climate surfaces (CSIROMK3.o, CCMA-CGCM3.1-T63 and GFDL-CM2; Ramirez \& Jarvis, 2008), representing a range of the available climate models and allowing us to examine the general robustness of our results. These three surfaces have been successfully used for the same purpose with birds (Loiselle et al., 2010).

\section{Species distribution models}

We used a geographical information system and species distribution models to describe the distribution of the kodkod under present climate conditions and under a climate change scenario. Distribution models have become an important tool to predict distributions of species, including potential changes in their geographical ranges as a result of climate change (Peterson et al., 2002; Araújo et al., 2005; Jeschke \& Strayer, 2008). We used models based on maximum entropy (MaxEnt v. 3.3.3k; Phillips et al., 2006), a presence-only modelling technique that performs well (Elith et al., 2006). Following Yost et al. (2008) we first ran a distribution model using all variables (19 climatic and two topographic) and applied a Jackknife analysis. We selected the variables that were relatively more important for the distribution of the species and that had low correlation values (Pearson correlation $<0.7$ ), to avoid collinearity and minimize redundancy (Table 1). To validate the model we ran it 100 times, randomly splitting the data into $75 \%$ to calibrate the model and $25 \%$ as test points, using a random seed each time and bootstrap replications. The final model was the average of all runs. To avoid bias from uneven sampling we used a kernel density bias file in MaxEnt (KramerSchadt et al., 2013). To evaluate the general performance of the models we calculated the area under the curve (AUC) for the receiver operating characteristic curve, incorporated in MaxEnt (Hanley \& McNeil, 1982; Baldwin, 2009). The model was then converted to a binary map of presenceabsence using the threshold where sensitivity and specificity intersect, which has been recommended in comparative studies (Liu et al., 2005).

\section{Constraints to the potential distribution}

To account for land use that is not suitable for the kodkod we clipped the potential distribution with the Globcover database, available at a resolution of 30 arc-seconds (ESA \& UCLouvain, 2010), thereby creating an adapted model. The species clearly avoids agricultural fields, pastures and other cleared areas (Dunstone et al., 2002), although native forest fragments continue to be adequate habitat in agricultural landscapes (Gálvez et al., 2013). We considered artificial surfaces and associated areas (urban areas $>50 \%$ ) and cultivated terrestrial areas as unsuitable for the kodkod but we took a conservative approach by retaining land uses such as roads, mosaic vegetation and cropland. We also excluded permanent snow and ice (Dunstone et al., 2002) and water bodies.

\section{Temporal turnover as a result of climate change}

When modelling temporal shifts in distribution ranges the equilibrium assumption is violated (Elith et al., 2010). 

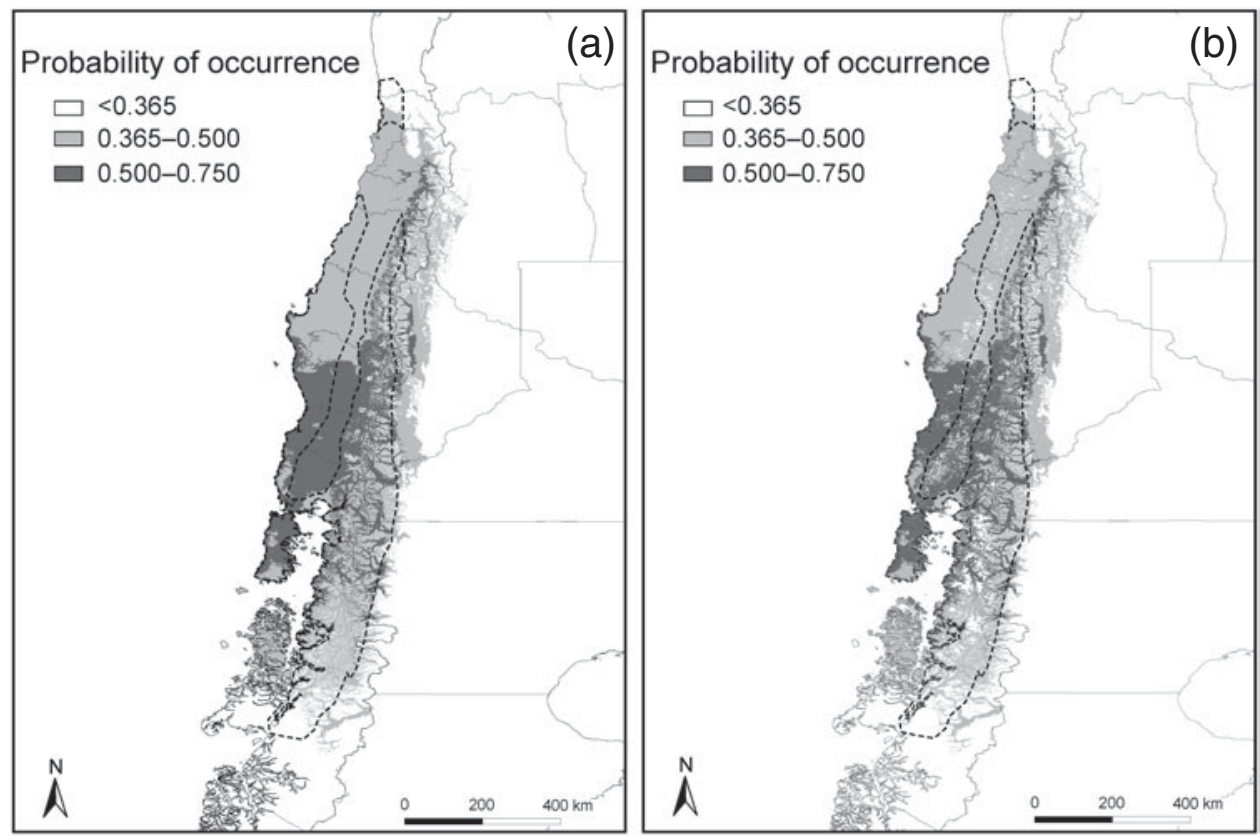

FIG. 2 (a) Modelled potential present distribution, and (b) potential present distribution (adapted model; see text for further details) of the kodkod. The species' distribution as recorded on the IUCN Red List (Acosta \& Lucherini, 2008) is represented by the dashed line.

Therefore, to define how models were extrapolated or interpolated, multivariate environmental similarity surfaces (MESS maps sensu Elith et al., 2010) were calculated using MaxEnt. As the potential model performed well $($ AUC $=0.901)$ we used all presence points to project the model into the future for each climate change scenario. We combined the results of the three climate change models in a consensus model, to overcome the problem of variability in predictions (Marmion et al., 2009), and applied the same threshold as for the present distribution model, excluding the same areas (Loiselle et al., 2010), assuming that degradation was irreversible and not including new transformed areas, but we did not exclude permanent snow or water bodies as their borders could change in the future.

\section{Current and future protection}

We obtained a layer of protected areas for the study region from the Secretaría de Medio Ambiente (Argentina) and from the Centro de Estudios Avanzados en Ecología y Biodiversidad and Biodiversity of the Pontificia Universidad Católica (Chile; Fig. 1b). We then performed a GAP analysis by superimposing the layer of protected areas with the binary maps of both the present and future distributions of the kodkod and calculating the percentage of the present and future area included in protected areas. As the distribution of the kodkod is not equally partitioned between Chile and Argentina we also calculated the percentage of the species' distribution in each country. We transformed grids of present and future distribution to polygons and simplified them to create files that can be opened in Google Earth (Google permissions, 2013).

\section{Results}

\section{Environmental variables and species distribution models}

Based on the Jackknife analysis of the preliminary model (variables that had a correlation $<0.7$ ) and biological significance, we present in Table 1 the five non-correlated climatic variables that have the greatest contribution to the present potential distribution of the kodkod. The most important variable was precipitation of the coldest quarter, which is related to snow limiting the kodkod's altitudinal distribution. In the preliminary MaxEnt models topographical variables did not have a significant contribution (and were therefore not used in the final models), probably because the kodkod occupies a wide range of altitudes (the presence points were from altitudes of $4-1,840 \mathrm{~m}$ ).

The models for the present potential distribution and future scenario performed well (AUC $0.901 \pm$ SD 0.0264 , threshold 0.3651 , and ACC $0.904 \pm$ SD 0.001, threshold 0.4104 , respectively). We applied equal training sensitivity and specificity values (presence probability) to transform the distributions to presence/absence maps (sensitivity refers to the proportion of presences correctly predicted and specificity is the proportion of absences correctly predicted). Based on these maps the present potential distribution of the kodkod is c. $339,903 \mathrm{~km}^{2}$ (Fig. 2a), of which $20 \%$ is in Argentina and $80 \%$ is in Chile. The present distribution was reduced by $5.5 \%$ when human land use was subtracted from the model (i.e. the adapted model; Fig. 2 b, Supplementary Fig. S1). Ten percent of this reduction was in Argentina and 90\% in Chile. Relative to the area of potential distribution in each country this represents a reduction of 6.3\% of the distribution in Chile and 2.8\% in Argentina. 


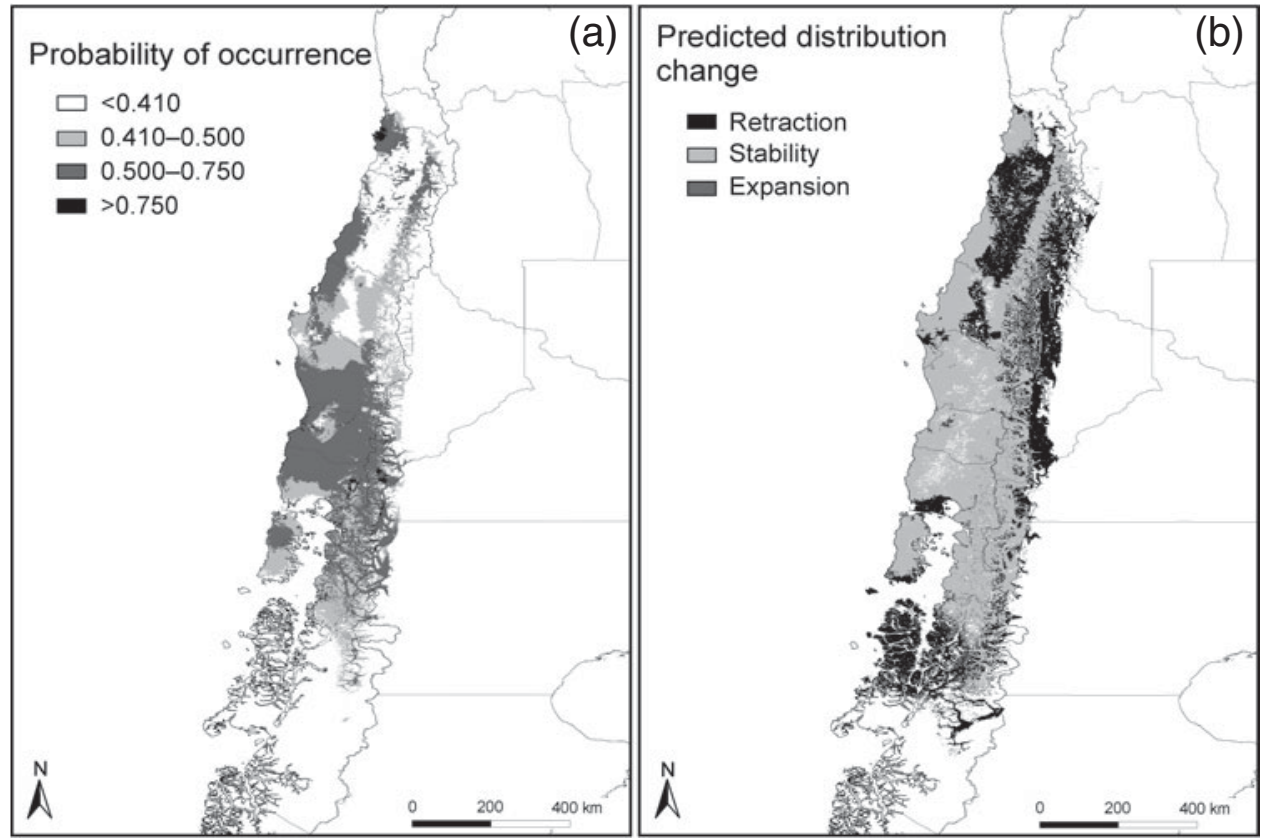

FIG. 3 (a) Modelled future distribution of the kodkod, and (b) predicted changes in its distribution from the present to 2050 .

\section{Temporal turnover as a result of climate change}

The MESS maps showed there were no differences between the training and prediction environments. After subtracting areas of human land use incompatible with the kodkod we found that only $61 \%$ of the kodkod's original potential distribution would be available in 2050 (Fig. 3a,b, Supplementary Fig. S2). The models indicate that climate change will have a greater impact in Argentina (58.6\%) than in Chile (32.5\%).

\section{Present and future representation in protected areas}

Of the present distribution of the kodkod $12.5 \%$ is represented in protected areas, of which $58 \%$ is in Argentina and $42 \%$ in Chile. Thus in Argentina $25 \%$ of the species' potential present distribution overlaps protected areas, but this is only $9 \%$ in Chile. If the present system of protected areas remains intact then $14 \%$ of the predicted future distribution of the kodkod will lie within protected areas. Of the future distribution in each country, $55 \%$ of suitable habitat in Argentina will remain protected in the future and $7.1 \%$ in Chile.

\section{Discussion}

Our model of the kodkod's present distribution performs well and therefore the geographical projection of the model is a reliable indicator of the species' potential distribution. The model estimated a potential distribution of $321,188 \mathrm{~km}^{2}$, which is greater than the previous estimates of $160,000 \mathrm{~km}^{2}$ (Oliveira, 1994; Nowell \& Jackson, 1996; Sunquist \&
Sunquist, 2002, 2009; Acosta \& Lucherini, 2008) and $189,000 \mathrm{~km}^{2}$ (Soutullo et al., 2005). Most likely our estimate is greater as a result of the absence of the species from localities with suitable habitat because of persecution (Ménoni, 1994; Silva-Rodríguez et al., 2007).

When human land use is accounted for, $94.5 \%$ of the modelled distribution remains; the largest portion of the $5.5 \%$ lost is in the central Matorral valley in Chile. This area contains the majority of Chile's human population and its largest cities, and current trajectories suggest that habitat transformation will continue but at an unknown rate (IUCN Cats Red List Workshop, 2007, in Acosta \& Lucherini, 2008).

Our modelling predicts that, including the most conservative approach to human land use, $39 \%$ of the kodkod's present potential distribution will be lost by 2050 as a result of climate change and changes in human land uses. A notable shift to higher elevations, in an area $20-50 \mathrm{~km}$ wide and $650 \mathrm{~km}$ long, is predicted at the eastern limit of the present distribution in Argentina (Fig. 3b). For the model of the future distribution we did not extract areas with permanent snow. Although the kodkod is presently restricted by permanent snow, these areas are predicted to become suitable in the future (Fig. $3 \mathrm{~b}$ ). If we consider the portion of the kodkod's present distribution not represented in protected areas that overlaps with Valdivian forests, and a mean deforestation rate of $1.86 \%$ per year (Armesto et al., 1992; Meneses, 2000; Echeverria et al., 2006; Altamirano \& Lara, 2010), then $98,830 \mathrm{~km}^{2}$ of Valdivian forest could be lost from the kodkod's potential habitat by 2050 . If we include this loss in our projections then $30 \%$ of the present potential distribution would be lost in the future. Consequently, the challenge for the future conservation of the species will be to 
reduce the deforestation rate or to incorporate landscapes outside protected areas (e.g. mosaic vegetation, native forest patches) into conservation plans.

In our model of the future distribution, areas with higher suitability ( $>0.75$; Fig. 3a) lie on the border between Argentina and Los Lagos Region in Chile. Although the GAP analysis indicated that $12.5 \%$ of the present and $14 \%$ of the kodkod's predicted future distribution will be represented in the current system of protected areas, this increase does not mean an increase in protected habitat but rather a reduction of the species' total potential range. More than $90 \%$ of the protected land is at high latitudes (south of $45^{\circ} \mathrm{S}$ ), and these areas may not be suitable for the kodkod (Gálvez et al., 2013). The occurrence of suitable habitat in protected areas does not necessarily mean that the species is present; further field surveys are needed. The situation in Argentina is problematic as climate change will leave only a small area of habitat suitable for the kodkod, but predicted human impacts on the transformation of habitat suitable for the kodkod is greater in Chile.

Models assume that a species is in equilibrium with its environment (Pearson \& Dawson, 2003). The potential present distribution of the kodkod predicted by our model is congruent with its previously described distribution, suggesting that the species is in equilibrium with current climate. But, as equilibrium depends on biological and abiotic interactions, and dispersal capacity, we do not know if the species can achieve this equilibrium under climate change scenarios.

Our models do not take into account interspecific relationships such as competition but the response to climate change of prey species and vegetation will have indirect impacts on the kodkod. The species has a wide trophic niche (Correa \& Roa, 2005) and thus it may be able to adapt to other habitats. The species currently appears to compete with Geoffroy's cat Leopardus geoffroyi in Argentina (Lucherini \& Luengos Vidal, 2003), and climate change may affect the two species in different ways, facilitating the presence of Geoffroy's cat in areas where it is currently absent (Strange et al., 2011).

Our model indicates that the impact of climate change will be greatest in the contact zone between the two subspecies L. guigna guigna and L. guigna tigrillo (Napolitano et al., 2013). The northernmost subspecies, L. guigna tigrillo, seems to occupy areas with less suitable habitat (Napolitano et al., 2013), and is less represented in current protected areas, and thus merits special attention. Based on genetic differentiation and population structure Napolitano et al. (2013) proposed five conservation units for the species. Of these the northern unit requires special consideration for conservation (Napolitano et al., 2013). Our model indicates that this unit may be threatened with extinction because suitable habitat will retract southwards and therefore no suitable habitat for this genetic unit may remain.
In summary, climate change will have a major negative impact on the kodkod, especially in Argentina. The kodkod's distribution closely matches that of the Valdivian Temperate Forest, and will still do so under scenarios of predicted climate change. Changes in human land use are higher in Chile than in Argentina but, given that the majority of the species' range is in Chile, conservation opportunities for the species there are greater. Both subspecies of kodkod will be affected by climate change but the effects on L. guigna tigrillo will be greater because of the predicted reduction in its potential habitat.

\section{Acknowledgements}

We thank Don Wilson, Kristofer Helgen, Alfred Gardner, Linda Gordon, Jeremy Jacobs (National Museum of Natural History, Washington, DC), Lawrence Heaney, William Stanley (Field Museum of Natural History, Chicago), Darrin Lunde, Eileen Westwig (American Museum of Natural History, New York), David Flores, Valentina Segura (Museo Argentina de Ciencias Naturales 'Bernardino Rivadavia', Buenos Aires), Mauro Lucherini and Estela Luengos Vidal (Colección del Grupo de Ecología Comportamental de Mamíferos, Bahía Blanca), Martín Monteverde (Centro de Ecología Aplicada, Junín de los Andes) for access to the specimens under their care, the IUCN Cat Specialist Group, especially Martín Monteverde and Gerardo Acosta-Jamett, for access to unpublished localities, Norberto Giannini for comments, Martin Fisher and the Conservation Leadership Programme Writing for Conservation workshop, and Carlos Navarro Racines (International Centre of Tropical Agriculture) for helping us with climate change data. This work was partially supported by Consejo Nacional de Investigaciones Científicas y Técnicas. MMM thanks a Short Term Visitor Fellowship Award at the National Museum of Natural History.

\section{References}

Acosta, G. \& Lucherini, M. (2008) Leopardus guigna. In IUCN Red List of Threatened Species v. 2013.2. Http://www.iucnredlist.org [accessed 4 April 2014].

Acosta-Jamett, G. \& Simonetti, J.A. (2004) Habitat use by Oncifelis guigna and Pseudalopex culpaeus in a fragmented forest landscape in central Chile. Biodiversity and Conservation, 13, 1135-1151.

Altamirano, A. \& Lara, A. (2010) Deforestación en ecosistemas templados de la precordillera andina del centro-sur de Chile. Bosque, 31, 53-64.

Araújo, M.B., Nogués-Bravo, D., Diniz-Filho, J.A.F., Haywood, A.M., Valdes, P.J. \& Rahbek, C. (2008) Quaternary climate changes explain diversity among reptiles and amphibians. Ecography, 31, 8-15.

Araújo, M.B., Pearson, R.G., Thuiller, W. \& Erhard, M. (2005) Validation of species-climate impact models under climate change. Global Change Biology, 11, 1504-1513. 
Armesto, J.J., Smith-Ramirez, C., León, P. \& Kalin Arroyo, M. (1992) Biodiversidad y conservación del bosque templado en Chile. Ambiente y Desarrollo, December, 19-24.

BALDWIN, R.A. (2009) Use of maximum entropy modeling in wildlife research. Entropy, 11, 854-866.

Burkart, R., Carpinetti, B., Molinari, R., Carminati, A., Martín, G., Balabusic, A. et al. (2007) Las áreas protegidas de la Argentina. Herramienta superior para la conservación de nuestro patrimonio natural y cultural. Administración de Parques Nacionales en colaboración de Fundación Vida Silvestre, Buenos Aires, Argentina.

Burns, C.E., Johnston, K.M. \& Schmitz, O.J. (2003) Global climate change and mammalian species diversity in US national parks. Proceedings of the National Academy of Sciences of the United States of America, 100, 11474-11477.

Cabrera, A. (1957) Catálogo de los Mamíferos de América del Sur. Parte I. Revista Museo Argentino Ciencias Naturales 'Bernardino Rivadavia', 4, 1-37.

Coldwell, V.L. (2008) An Analysis of Methodologies Used to Study Medium and Large Mammals in the Valdivian Temperate Rainforests of Central-Southern Chile. Imperial College, London, UK.

CONAMA (2007) Diario oficial de la republica de Chile, 10. Chile.

Conrad, K.F., Warren, M.S., Fox, R., Parsons, M.S. \& Worwod, I.P. (2006) Rapid declines of common, widespread British moths provide evidence of an insect biodiversity crisis. Biological Conservation, 132, 279-291.

Correa, P. \& RoA, A. (2005) Relaciones tróficas entre Oncifelis guigna, Lycalopex culpaeus, Lycalopex griseus y Tyto alba en un ambiente fragmentado de la zona central de Chile. Mastozoología Neotropical, 12, 57-60.

Díaz, G.B. \& Ojeda, R.A. (eds) (2000) Libro Rojo de Mamíferos Amenazados de la Argentina. Sociedad Argentina para el Estudio de los Mamíferos, Mendoza, Argentina.

Diaz, H.F. \& BRADLEY, R.S. (1997) Temperature variations during the last century at high elevation sites. Climatic Change, 36, 253-279.

DIVA-GIS, (2013) Http://www.diva-gis.org [accessed April 2013].

Dunstone, N., Durbin, L., Wylie, I., Freer, R., AcostaJametт, G., Mazzolli, M. \& Rose, S. (2002) Spatial organization, ranging behaviour and habitat use of the kodkod (Oncifelis guigna) in southern Chile. Journal of Zoology (London), 257, 1-11.

Echeverria, C., Coomes, D., Salas, J., Rey-Benayas, J.M., Lara, A. \& Newton, A. (2006) Rapid deforestation and fragmentation of Chilean Temperate Forests. Biological Conservation, 130, 481-494.

Elith, J., Graham, C.H., Anderson, R.P., Dudík, M., Ferrier, S., Guisan, A. et al. (2006) Novel methods improve prediction of species' distributions from occurrence data. Ecography, 29, 129-151.

Elith, J., Kearney, M. \& Phillips, S. (2010) The art of modelling range-shifting species. Methods in Ecology and Evolution, 1, 330-342.

ESA \& UCLouvain (2010) Land cover, Central and South America (GlobCover 2009). Http://www.un-spider.org/links-and-resources/ data-sources/globcover-esa [accessed 7 June 2012].

FAO (Food and Agriculture Organization of the UN) (2001) Pastoralism in the New Millennium. FAO, Rome, Italy.

Freer, R.A. (2004) The Spatial Ecology of the Guina (Oncifelis guigna) in Southern Chile. PhD thesis. Department of Biological Sciences, University of Durham, UK.

Gálvez, N., Hernández, F., Laker, J., Gilabert, H., Petitpas, R., Bonacic, C. et al. (2013) Forest cover outside protected areas plays an important role in the conservation of the Vulnerable guiña Leopardus guigna. Oryx, 47, 251-258.

Google Permissions (2013) Http://www.google.com/permissions/ geoguidelines.html [accessed 4 April 2013].
Hanley, J.A. \& McNeil, B.J. (1982) The meaning and use of area under the receiver operating characteristic (ROC) curve. Radiology, $143,29-36$.

Hernandez, P.A., Graham, C.H., Master, L.L. \& Albert, D.L. (2006) The effect of sample size and species characteristics on performance of different species distribution modeling methods. Ecography, 29, 773-785.

Hijmans, R.J., Cameron, S.E., Parra, J.L., Jones, P.G. \& Jarvis, A. (2005) Very high resolution interpolated climate surfaces for global land areas. International Journal of Climatology, 25, 1965-1978.

Huber, A. (1979) Estimación empírica de las características hidrológicas de Chile. Agro Sur, 7, 57-65.

Hughes, L. (2000) Biological consequences of global warming: is the signal already apparent? Trends in Ecology and Evolution, 15, 56-61.

INNES, J.L. (1991) High-altitude and high-latitude tree growth in relation to past, present and future global climate change. Holocene, $1,168-173$.

Jennings, M.D. (200o) Gap analysis: concepts, methods, and recent results. Landscape Ecology, 15, 5-20.

Jeschke, J.M. \& Strayer, D.L. (2008) Usefulness of bioclimatic models for studying climate change and invasive species. Annals of the New York Academy of Sciences, 1134, 1-24.

Kramer-Schadt, S., Niedballa, J., Pilgrim, J.D., Schröder, B., Lindenborn, J., Reinfelder, V. et al. (2013) The importance of correcting for sampling bias in MaxEnt species distribution models. Diversity and Distributions, 1-14.

Liu, C., Berry, P.M., Dawson, T.P. \& Pearson, R.G. (2005) Selecting thresholds of occurrence in the prediction of species distributions. Ecography, 28, 385-393.

Loiselle, B.A., Graham, C.H., Goerck, J.M. \& Ribeiro, M.C. (2010) Assessing the impact of deforestation and climate change on the range size and environmental niche of bird species in the Atlantic forests, Brazil. Journal of Biogeography, 37, 1288-1301.

Lucherini, M. \& Luengos Vidal, E. (2003) Intraguild competition as a potential factor affecting the conservation of two endangered cats in Argentina. Endangered Species Update, 20, 211.

Margules, C.R. \& Pressey, R.L. (2000) Systematic conservation planning. Nature, 405, 243-253.

Marinaro, S., Grau, H.R. \& Aráoz, E. (2012) Extensión y originalidad en la creación de parques nacionales en relación a cambios gubernamentales y económicos de la Argentina. Ecología Austral, 22, 1-10.

Marino, J., Bennett, M., Cossios, D., Iriarte, A., Lucherini, M., Pliscoff, P. et al. (2011) Bioclimatic constraints to Andean cat distribution: a modelling application for rare species. Diversity and Distributions, 17, 311-322.

Marmion, M., Parviainen, M., Luoto, M., Heikininen, R.K. \& Thuiller, W. (2009) Evaluation of consensus methods in predictive species distribution modelling. Diversity and Distributions, 15, 59-69.

Meneses, M. (2000) Cambios en el uso del suelo y expansión de plantaciones. Ambiente y Desarrollo, XVI, 86-95.

Ménoni, E. (1994) Statut, évolution et facteurs limitants des populations francaises de grand tétras Tetrao urogallus synthèse bibliographique. Gibier Faune Sauvage Game and Wildlife, 11, 97-158.

Napolitano, C., Sanderson, J., Johnson, W.E., O’Brien, S.J.O., Ritland, K. \& Poulin, E. (2013) Population genetics of the felid Leopardus guigna in Southern South America: identifying intraspecific units for conservation. In Molecular Population Genetics, Evolutionary Biology and Biological Conservation of Neotropical Carnivores' (eds M. Ruiz-García \& J.M. Shostell), p. 129. Nova Publishers, New York, USA. 
Nowell, K. \& Jackson, P. (1996) Wild Cats: Status Survey and Conservation action Plan. IUCN/Species Survival Commission Cat Specialist Group, Gland, Switzerland.

Oliveira, T.G. (1994) Neotropical Cats: Ecology and Conservation. Editora da Universidade Federal do Maranhão, São Luis, Brazil.

Olson, D.M., Dinerstein, E., Wikramanayake, E.D., Burgess, N.D., Powell, G.V., Underwood, E.C. et al. (2001) Terrestrial ecoregions of the world: a new map of life on earth. BioScience, 51, 933-938.

Opdam, P. \& Wascher, D. (2004) Climate change meets habitat fragmentation: linking landscape and biogeographical scale levels in research and conservation. Biological Conservation, 117, 285-297.

Osgood, W.H. (1943) The Mammals of Chile. Field Museum of Natural History, Chicago, USA.

Parmesan, C. \& Yohe, G. (2003) A globally coherent fingerprint of climate change impacts across natural systems. Nature, 421, $37-42$.

Pearson, R.G. \& Dawson, T.P. (2003) Predicting the impacts of climate change on the distribution of species: are bioclimate envelope models useful? Global Ecology and Biogeography, 12, 361-371.

Peterson, A.T., Ortega-Huerta, M.A., Bartley, J., Sánchez-Cordero, V., Soberón, J., Buddemeier, R.H. \& StOcKWell, D.R.B. (2002) Future projections for Mexican faunas under global climate change scenarios. Letters to Nature, 416, 626-629.

Phillips, S.J., Anderson, R.P. \& Schapire, R.E. (2006) Maximum entropy modeling of species geographic distributions. Ecological Modelling, 190, 231-259.

Pierce, D.W., Barnett, T.P., Santer, B.D. \& Gleckler, P.J. (2009) Selecting global climate models for regional climate change studies. Proceedings of the National Academy of Sciences of the United States of America, 106, 8441.

Ramirez, J. \& Jarvis, A. (2008) High Resolution Statistically Downscaled Future Climate Surfaces. International Center for Tropical Agriculture, CGIAR Research Program on Climate Change, Agriculture and Food Security, Cali, Colombia.

Regan, H.M., Colyvan, M. \& Burgman, M.A. (2000) A proposal for fuzzy International Union for the Conservation of Nature (IUCN) categories and criteria. Biological Conservation, 92, 101-108.

Rodrigues, A.S.L., Andelman, S.J., Bakarr, M.I., Boitani, L., Brooks, T.M., Cowling, R.M. et al. (2004) Effectiveness of the global protected area network in representing species diversity. Nature, 428, 640-643.

Root, T.L., Price, J.T., Hall, K.R., Schneider, S.H., Rosenzweig, C. \& Pounds, J.A. (2003) Fingerprints of global warming on wild animals and plants. Nature, 421, $54-57$.

Sánchez-Fernández, D., Lobo, J.M. \& HernándezManrique, O.L. (2011) Species distribution models that do not incorporate global data misrepresent potential distributions: a case study using Iberian diving beetles. Diversity and Distributions, 17, 163-171.

Schipper, J., Chanson, J.S., Chiozza, F., Cox, N.A., Hoffmann, M., Katariya, V. et al. (2008) The status of the world's land and marine mammals: diversity, threat, and knowledge. Science, 322, 225-230.
Silva-Rodríguez, E.A., Ortega-Solís, G.R. \& Jiménez, J.E. (2007) Human attitudes toward wild felids in a human-dominated landscape of southern Chile. Cat News, 46, 19-21.

Soutullo, A., Dodsworth, S., Heard, S.B. \& Mooers, A. (2005) Distribution and correlates of carnivore Phylogenetic diversity across the Americas. Animal Conservation, 8, 249-258.

Strange, N., Jellesmark, Thorsen B., Bladt, J., Wilson, K.A. \& RAHBEK, C. (2011) Conservation policies and planning under climate change. Biological Conservation, 114, 2968-2977.

Sunquist, M.E. \& Sunquist, F.C. (2002) Wild Cats of the World. The University of Chicago Press, Chicago, USA.

Sunquist, M.E. \& Sunquist, F.C. (2009) Family Felidae (cats). In Handbook of the Mammals of the World (eds D.E. Wilson \& R.A Mittermeier), pp. 54-169. Lynx Edicions, Barcelona, Spain.

TAPIA FRIZ, C.E. (2005) Estudio de la actividad de macromamíferos silvestres en fragmentos de bosque nativo con distintos grados de intervención antrópica de la provincia de Valdivia. Veterinary degree thesis. University Austral of Chile, Valdivia, Chile.

Thomas, C.D., Cameron, A., Green, R.E., Bakkenes, M., Beaumont, L.J., Collingham, Y.C. et al. (2004) Extinction risk from climate change. Nature, 427, 145-148.

Thorn, J., Nijman, V., Smith, D. \& Nekaris, K. (2009) Ecological niche modelling as a technique for assessing threats and setting conservation priorities for Asian slow lorises (Primates: Nycticebus). Diversity and Distributions, 15, 289-298.

Tôrres, N.M., De Marco, P. Jr, Filho, J.A.F. \& Silveira, L. (2008) Jaguar distribution in Brazil: past, present and future. CAT News, 4, 1-5.

Walker, S., Novaro, A., Monteverde, M., Sanguinetti, J., Rossio, P., Mutcol, S. et al. (2003) Efectos del disturbio humano sobre el gato huiña y otros carnívoros en el Parque Nacional Lanín. Report presented to the Administration of National Parks, Argentina.

Wilson, D.E. \& Reeder, D.M. (eds) (2005) Mammal Species of the World: A Taxonomic and Geographic Reference, 3 rd ed. Johns Hopkins University Press, Baltimore, USA.

Wilting, A., Cord, A., Hearn, A.J., Hesse, D., Mohamed, A., Traenoldt, C. et al. (2010) Modelling the species distribution of flat-headed cats (Prionailurus planiceps), an Endangered South-east Asian small felid. PLoS ONE, 5(3), e9612.

WWF (2006) WildFinder. Http://www.worldwildlife.org/science/ wildfinder/ [accessed 7 June 2012].

Yost, A.C., Petersen, S.L., Gregg, M. \& Miller, R. (2008) Predictive modeling and mapping sage grouse (Centrocercus urophasianus) nesting habitat using Maximum Entropy and a long-term dataset from Southern Oregon. Ecological Informatics, $3,375-386$

\section{Biographical sketches}

Griet Cuyckens is interested in the distribution and ecology of Neotropical felids, particularly in applying geographical information systems to conservation issues. She has worked with several field projects on threatened species in Argentina. Miriam Morales' main research interest is the study of the functional morphology of felids. Marcelo Togneld is interested in the application of spatial analysis, species distribution models and conservation planning to the conservation of biodiversity. 